\title{
〔81]ガスクロマトグラフによるモノマー反応性比の測定
}

第 1 報 アクリル酸メチルと塩化ビニリデンのラジカル

重合におけるモノマー反応性比

(1966 年 1 月 18 日受理)

\section{伊保内 賢*}

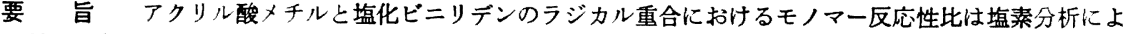

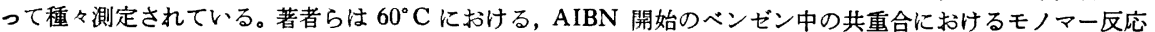
性比をガスクロマトグラフで求め, 塩素分析值と一致したので報告する。カラム温度は $80^{\circ} \mathrm{C}$, 通気速度 $30 \mathrm{~m} l$ min, キャリヤーガスはヘリウムを用い, 重合索停止した試料在そのままガスクロマトグラフに注入し, 未重 合モノマー量を定量し、モノマー反応性比を計算した。
\end{abstract}

\section{1. 緒言}

共重合体のモノマー反応性比を求めるためにガスクロ マトグラフを用いることがあるが，従来は主に共重合体 を熱分解して定量している。重合反応の試料をそのまま ガスクロマトグラフに注入すれば，その時間における末 反応モノマー量が定量され, 収量と共重合反応性比が求 められる。アクリル酸メチルと塩化ビニリデンのラジカ ル共重合において, その共重合反応性比をガスクロマト グラムによって求めたところ，塩素分析による既報” の 値と一致したので報告する。

\section{2. 実験}

\section{1 モノマー, 溶媒など}

アクリル酸メチル (MA) は常法によって精製し, 塩化 カルシウムで脱水後, ウィットマー蒸留器を付して 2 回 蒸留して, 沸点 $79 \sim 79.5^{\circ} \mathrm{C}$ 留分を捕集し, 重合直前再 蒸留してその中間留分を用いた。

塩化ビニリデン (VDC) は空素父流中で 2 回蒸留し, 沸点 $31 \sim 32.5^{\circ} \mathrm{C}$ 留分を水トラップに捕集して用いた。

ベンゼン $(\mathrm{Bz})$ 什市販一級品を精製した後, 蒸留し, 金 属ナトリウムで脱水後蒸留して用いた。

開始凧の $\alpha, \alpha^{\prime}$-アゾビスイソブチロニトリル (AIBN)

は1回再結晶を行なった。

Table 1. Calibration of methyl acrylate (MA) and vinylidene chloride (VDC).

\begin{tabular}{|c|c|c|c|c|c|c|c|c|c|c|}
\hline \multirow{2}{*}{ No. } & \multicolumn{3}{|c|}{ Monomer standard } & \multicolumn{5}{|c|}{$\begin{array}{l}\text { Relative peak area of gas chlomatogram } \\
\text { Mol ratio of monomer to benzene }\end{array}$} & \multicolumn{2}{|c|}{$\begin{array}{l}\text { Ratio of peak area o } \\
\text { gas chromatogram }\end{array}$} \\
\hline & MA (g) & $\operatorname{VDC}(\mathrm{g})$ & $\mathrm{Bz}(\mathrm{g})$ & MA & VDC & $\mathrm{Bz}$ & $M_{M} / M_{B}$ & $M_{V} / M_{B}$ & $S_{M} / S_{B}$ & $S_{V} / S_{B}$ \\
\hline 1 & 0.48 & 1.22 & 0 & 5.7 & $12.1^{*}$ & - & $(0.49)$ & $(1.10)$ & $(0.57)$ & $(1.21)$ \\
\hline 2 & 0.96 & 1.22 & 0 & 10.8 & $12.1^{*}$ & - & $(0.99)$ & $(1.10)$ & $(1.08)$ & $(1.21)$ \\
\hline 3 & 0.48 & 1.22 & 0.88 & 5.7 & 12.1 & 10 & 0.49 & 1.10 & 0.57 & 1.21 \\
\hline 4 & 0.96 & 0.61 & 0.88 & 10.6 & 5.9 & 10 & 0.99 & 0.55 & 1.06 & 0.59 \\
\hline 5 & 0.96 & 1.22 & 0.88 & 10.8 & 12.0 & 10 & 0.99 & 1.10 & 1.08 & 1.20 \\
\hline 6 & 0.96 & 1.22 & 0.88 & 10.6 & 12.2 & 10 & 0.99 & 1.10 & 1.06 & 1.22 \\
\hline 7 & 0.96 & 2.44 & 0.88 & 10.8 & 23.2 & 10 & 0.99 & 2.21 & 1.08 & 2.32 \\
\hline 8 & 1.92 & 1.22 & 0.88 & 22.9 & 12.2 & 10 & 1.97 & 1.10 & 2.29 & 1.22 \\
\hline 9 & 2.88 & 0 & 2.64 & 10.7 & - & 10 & 0.99 & - & 1.07 & - \\
\hline 10 & " & 0 & 5.24 & 5.8 & - & 10 & 0.50 & - & 0.58 & - \\
\hline 13 & 1.92 & 1.22 & 2.64 & 7.3 & 4.1 & 10 & 0.66 & 0.37 & 0.73 & 0.41 \\
\hline 16 & 1.44 & 1.83 & 2.64 & 5.5 & 6.0 & 10 & 0.50 & 0.55 & 0.55 & 0.61 \\
\hline 18 & 0.96 & 2.44 & 2.64 & 3.7 & 8.1 & 10 & 0.33 & 0.74 & 0.37 & 0.81 \\
\hline
\end{tabular}

* Relative peak area of VDC was fix 12.1 as standard.

*要知県工業指導所化学部(名古屋市千種区花田町 3-58) 


\section{2 検量線}

検量線図を作製するため, 微量の禁止剤の存在下で Table 1 の上らな組成の試料を調製し, その $0.01 \sim 0.02$ $\mathrm{m} l$ をガスクロマトグラフに注入し検量線を求めた。そ の結果は Fig 1,2 に示寸ように, アクリル酸メチル, お

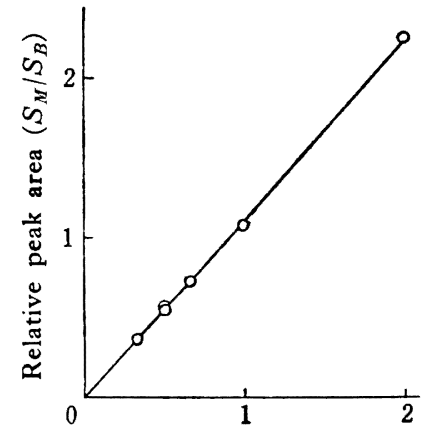

Mol ratio $\left(\left[\mathrm{M}_{M}\right] /\left[\mathrm{M}_{B}\right]\right)$

Column: $2 \mathrm{~m}$, silicon DC-550 (Shimadzu), $80^{\circ} \mathrm{C}$ Carrier gas: He, Flow rate: $30 \mathrm{~m} l / \mathrm{min}$

Fig. 1. Calibration curve for methyl acrylate internal normalization by benzene.

上び塩化ビニリデンのベンゼンに対する検量線はいずれ も㨁線で，しかも，同じ勾配を示している。すなわち，ア クリル酸メチルのモル漘度を $M_{M}$, 塩化ビニリデンのモ 儿濃度を $M_{V}$, ぶンゼンのモ儿擞度を $M_{B}$ とし, それぞ れのガスクロマトグラムピーク面積を $S_{M}, S_{V}, S_{B}$ と すれば Fig 1, 2 上り，

$$
\frac{M_{M}}{M_{B}}=0.92 \frac{S_{M}}{S_{B}}, \quad \frac{M_{V}}{M_{B}}=0.91 \frac{S_{V}}{S_{B}}
$$

ゆえに以下の計算においてて

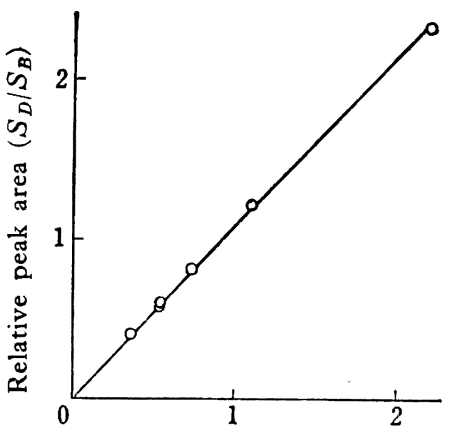

Mol ratio $\left(\left[\mathrm{M}_{D}\right] /\left[\mathrm{M}_{B}\right]\right)$

Column: $2 \mathrm{~m}$, silicon DC-550 (Shimadzu), $80^{\circ} \mathrm{C}$ Carrier gas: He, Flow rate: $30 \mathrm{~m} l / \mathrm{min}$

Fig. 2. Calibration curve for vinylidene chloride internal normalization by benzene.

$$
\frac{M_{M}}{M_{V}} \fallingdotseq \frac{S_{M}}{S_{V}}
$$

として行なった。

この測定条件はキャリヤーガスにーリウムを用い，流 量は $30 \mathrm{~m} l / \mathrm{min}$, カラム長さ $2 \mathrm{~m}$, 充てん郕としてシリコ ン DC-550 (島津製作所製), 粒度は 30 60メッシュの ものを用いた。ガスクロマトグラフは日立製高感度ガス クロマトグラフ KGL-2 型を用いた。カラム温度 $80^{\circ} \mathrm{C}$, 蒸発器温度は $90^{\circ} \mathrm{C}$ である。

\section{3 重合実験}

重合は試験管を用い, 開始剤, 溶媒, モノマーを所定 量加えた後, 溶封して, $60^{\circ} \mathrm{C}$ の恒温水槽中で光を遮断 して重合した。重合終了徭, $0^{\circ} \mathrm{C}$ に冷却し, 開封して直 ちにガスクロマトグラフに注入した。測定値としてピー ク面䄸を用い, 重量法で求めた。ベンゼンとアクリル酸

\begin{tabular}{|c|c|c|c|c|c|c|c|c|c|}
\hline \multirow{2}{*}{ No. } & \multicolumn{2}{|c|}{ Monomer } & \multirow{2}{*}{$\begin{array}{l}\text { Solvent } \\
\mathrm{Bz}(\mathrm{g})\end{array}$} & \multirow{2}{*}{$\begin{array}{r}\text { AIBN } \\
(\mathrm{mg})\end{array}$} & \multirow{2}{*}{$\begin{array}{c}\text { Polymerization } \\
\text { time } \\
(\mathrm{min})\end{array}$} & \multirow{2}{*}{$\begin{array}{c}\text { Conversion } \\
\text { (g) }\end{array}$} & \multicolumn{3}{|c|}{$\begin{array}{l}\text { Relative peak area of } \\
\text { unreact monomer }\end{array}$} \\
\hline & $\mathrm{MA}(\mathrm{g})$ & $\operatorname{VDC}(\mathrm{g})$ & & & & & MA & VDC & $\mathrm{Bz}$ \\
\hline 11 & 2.28 & 0 & 2.64 & 4 & 70 & 0.028 & 9.7 & 0 & 10 \\
\hline 12 & 2.28 & 0 & 2.64 & 4 & 100 & 0.204 & 9.2 & 0 & 10 \\
\hline 13 & 1.92 & 1.22 & 2.64 & 0 & 0 & 0 & 7.3 & 4.1 & 10 \\
\hline 14 & 1.92 & 1.22 & 2.64 & 4 & 70 & 0.188 & 6.9 & 4.0 & 10 \\
\hline 15 & 1.92 & 1.22 & 2.64 & 4 & 100 & 0.370 & 6.75 & 3.7 & 10 \\
\hline 16 & 1.44 & 1.83 & 2.64 & 0 & 0 & 0 & 5.5 & 6.0 & 10 \\
\hline 17 & 1.44 & 1.83 & 2.64 & 4 & 75 & 0.177 & 4.95 & 5.3 & 10 \\
\hline 18 & 0.96 & 2.44 & 2.64 & 0 & 0 & 0 & 3.7 & 8.1 & 10 \\
\hline 19 & 0.96 & 2.44 & 2.64 & 4 & 75 & 0.126 & 3.4 & 7.4 & 10 \\
\hline 20 & 0 & 3.66 & 5.28 & 3 & 30 & 0.020 & 0 & 5.85 & 10 \\
\hline
\end{tabular}

Table 2. Coplymerization of methyl acrylate (MA) and vinylidene chloride (VDC) at $60^{\circ} \mathrm{C}$. 
メチルはほほ同じ沸点を示すが，本条件でははっきり分 離し内部標準として用いるのに十分であった。

\section{4 ポリマー熱分解}

ガスクロマトグラフに注入する試料はモノマー, 溶媒 ポリマーの混合物であるから，ポリマーの分解を検討す る必要がある。ポリ塩化ビニリデンはベンゼンに不溶の ため, 共重合体 (No. 19), およびポリアクリル酸メチ ルをベンゼン，アセトンにそれぞれ溶解し，ガスクロマ トグラフに注入したが，溶媒のピークのみが現われ，本 実験条件下では, ポリマーの分解物が検出されなかった ので,一応分解はないと結論した。

\section{3. 結果と考察}

\section{1 実験結果}

実験結果を Table 2 に示す, この值用い,(1) 式を 用いて計算した結果を Table 3 に示し, その FinemanRoss のプロットを Fig. 3 亿示す。この方法で $r_{1}, r_{2}$ を

Table 3. Calculation of Fineman-Ross method.

\begin{tabular}{c|c|c|c|c}
\hline \hline No. & $F$ & $f$ & $F(f-1) / f$ & $F^{2} / f$ \\
\hline $13 \sim 15$ & 1.77 & 1.37 & 0.477 & 2.28 \\
$16 \sim 17$ & 0.89 & 0.785 & -0.255 & 1.01 \\
$18 \sim 19$ & 0.44 & 0.43 & -0.58 & 0.45 \\
\hline
\end{tabular}

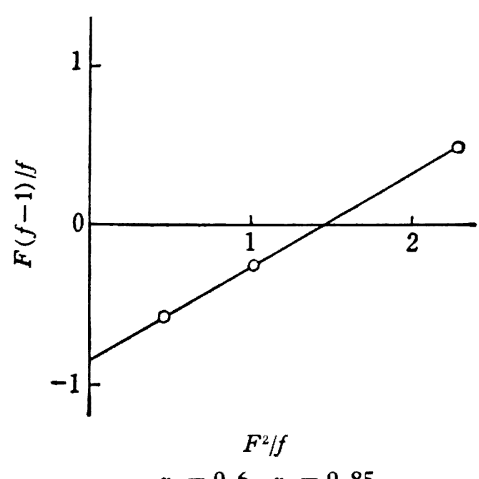

Fig. 3. Fineman-Ross plot of gas chromatogram method.

求め既報の值を比較すると Table + のようである。

Table 4. Monomer reactivity ratio of methyl acrylate $\left(M_{1}\right)$ and vinylidene chloride $\left(\mathrm{M}_{2}\right)$ at radical copolymerization.

\begin{tabular}{c|c|c}
\hline \multicolumn{1}{c|}{ Analytical method } & $r_{1}$ & $r_{2}$ \\
\hline Chlorine analytical method ${ }^{12}$ & $0.84 \pm 0.06$ & $0.99 \pm 0.10$ \\
Gas chromatogram method & $0.60 \pm 0.1$ & $0.85 \pm 0.1$ \\
\hline
\end{tabular}

\section{2 計算式}

本報では (1) 式の関倸をもつため, 非常に計算が簡単 であるが，一般にはこの関係は成立しない。

いまモノマーA，およびモノマーBが共重合すると考 えてモノマーA, モノマーB および溶媒 $\mathrm{S}$ の初浱度をそ れぞれ $M_{A 1}, M_{B 1}, M_{S}$, 一定時間重合後のモル濃度を $M_{A 2}, M_{B 2}, M_{S}$ 同様にガスクロマトグラムピーク面積 を $S_{A 1}, S_{B 1}, S_{S} ; S_{A 2}, S_{B 2}, S_{S}$ とすれば検量線より，

$$
\frac{S_{A}}{S_{S}}=a \frac{M_{A}}{M_{S}} \quad \text { (2), } \quad \frac{S_{B}}{S_{S}}=b \frac{M_{B}}{M_{S}}
$$

微分法で反応性比を求めるには $M_{A} / M_{B}, d M_{A} / d M_{B}$ が必要でありこれとピーク面積との関係は (2), (3) 式 より,

$$
\begin{aligned}
& \frac{S_{A}}{S_{B}}=\frac{\frac{S_{A}}{S_{S}}}{\frac{S_{B}}{S_{S}}}=\frac{a \frac{M_{A}}{M_{S}}}{b \frac{M_{B}}{M_{S}}}=\frac{a}{b} \cdot \frac{M_{A}}{M_{B}}=k \frac{M_{A}}{M_{B}} \\
& \frac{M_{A}}{M_{B}}=\frac{1}{k} \cdot \frac{S_{A}}{S_{B}} \\
& \text { ここに } k=\frac{a}{b} \text {, 同様に }
\end{aligned}
$$

$$
\begin{aligned}
& \frac{d M_{A}}{d M_{B}}=\frac{M_{A 1}-M_{A 2}}{M_{B 1}-M_{B 2}}=\frac{\frac{M_{A 1}}{M_{S}}-\frac{M_{A 2}}{M_{S}}}{\frac{M_{B 1}}{M_{S}}-\frac{M_{B 2}}{M_{S}}} \\
& =\frac{\frac{1}{a}\left(\frac{S_{A 1}}{S_{S}}-\frac{S_{A 2}}{S_{S}}\right)}{\frac{1}{b}\left(\frac{S_{B 1}}{S_{S}}-\frac{S_{B 2}}{S_{S}}\right)}=\frac{b}{a} \frac{S_{A 1}-S_{A 2}}{S_{B 1}-S_{B 2}} \\
& \text { ゆえに } \frac{d M_{A}}{d M_{B}}=\frac{1}{R} \cdot \frac{d S_{A}}{d S_{B}}
\end{aligned}
$$

(4)，(5)式を微分式に代入すれば

$$
r_{B}=\frac{1}{k^{3}} \cdot \frac{S_{A 1}}{S_{B 1}}\left[\frac{S_{B 1}-S_{B 2}}{S_{A 1}-S_{A 2}}\left(k+\frac{S_{A 1}}{S_{B 1}} r_{A}\right)-k^{2}\right]
$$

Fineman-Ross の方法では,

$$
F=\frac{M_{A}}{M_{B 1}}=\frac{1}{k} \cdot \frac{S_{A 1}}{S_{B 1}} f=\frac{d M_{A}}{d M_{B}}=\frac{1}{k} \cdot \frac{S_{A 1}-S_{A 2}}{S_{B 1}-S_{B 2}}
$$

ゆえに $F^{\prime}=\frac{S_{A 1}}{S_{B 1}}, \quad f^{\prime}=\frac{S_{A 1}-S_{A 2}}{S_{B 1}-S_{B 2}}$ とすれば,

$$
\frac{F^{\prime}\left(f^{\prime}-1\right)}{f^{\prime}}=\frac{F^{\prime 2}}{f^{\prime}} r_{A}-k r_{B}
$$


$r_{B}$ が $k$ 倍, すなわち, 切片が $k r_{B}$ であることが示さ れる。

また，積分式でも，

$$
\begin{gathered}
r_{B}=\frac{\log \frac{S_{B 1}}{S_{B 2}}-\frac{1}{p} \log \frac{k-p \frac{S_{A 2}}{S_{B 2}}}{k-p \frac{S_{A 1}}{S_{B 1}}}}{k-p \frac{S_{A 2}}{S_{B 2}}} \frac{S_{A 1}}{k-p \frac{S_{A 1}}{S_{B 1}}}+\log \frac{S_{A 2}}{S_{A 2}} \\
p=\frac{1-r_{A}}{1-r_{B}}
\end{gathered}
$$

すなわち，1の代わりに $k$ を代入した式となる。この (6) 〜 (9) 式を用いて直接ピーク面積比から求为る方が簡 単である。

モノマー反応性比は重合率と無関倸であるが，できう 机ば停止剤を加えて重合を完全に停止させ，重合時間を 明確にしておけば，ガスクロマトグラムの精度などを検 討する際, および収量の計算に便利である。本報では溶 媒があって重合も比較的遅く, $0^{\circ} \mathrm{C}$ に泠却した場合に, 重合はほとんど進行しない。また, 重合終了後, 短時間 内にガスクロマトグラフに注入しているので， $0^{\circ} \mathrm{C}$ の泠 却で十分である。同一試料をくり返し注入しうる条件で あればよいと思う。

また，モノマー反応性比を 1 試料の重合に扔いて, 一 定時間おきに，少量の試料を採取してガスクロマトグラ フに注入し, そのモノマー組成変化を求むれば, 桜田の 方法”によってモノマー反応性比が求的られるはずであ る。しかし, 本報の場合, モノマー反応性比がほぼ 1 対 1 のため，モノマー組成の変化率が少ないので，この方 法によって, モノマー反応性比は求めにくい。また, $r_{1}$

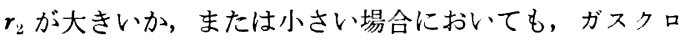
マトグラムより得られる值が元素分析におけるような精 度がないため，モノマー反応性比の小さいモノマーにお いて誤差が大きくなり，モノマー反応性比を正確に求め ることができない。したがって，ガスクロマトグラフに よってモノマー反応性比を求めるには，本報のように仕 込み比の異なった試料の初期重合の実験値を用いて計算 すべきである。

本報のモノマー反応性比の誤差は \pm 0.1 であるが, 交 点法により誤差を求めると, ほぼ 1 点で交わり, 誤差は もっと小さいことになるが，ガスクロマトグラムの誤差 が $5 \%$ 内外あり, *1 したがってモノマー反応性比の誤差 が 10\%ぐらいとなった。したがって充てん戍, 温度。
ガス流量などの条件および積分チャート，超高感度機器 の使用によって，この誤差はさらに小さくなるものと思 われる。

\section{3 共重合物の赤外吸収スペクトル}

アクリル酸メチルと塩化ビニリデンのラジカル共重合 については Mayo らの報告”もあり，ほぼ $r_{1} / r_{2}=1$ で 共重合することが知られている。

著者もガスクロマトグラフに注入した各試料より共重 合物を精製し, 赤外吸収スペクトルによって共重合して いることを確認している。その一例を Fig. 4 に示した。

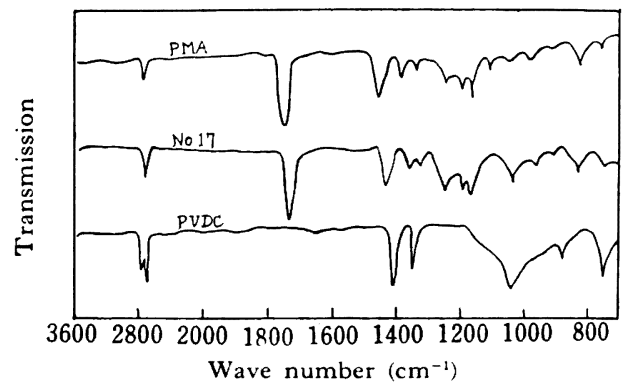

Fig. 4. IR Spectrum of copolymer ot methyl acrylate and vinylidene chloride.

共重合物はポリアクリル酸メチル (PMA)，およびポリ塩 化ビニリデン(PVDC)のいずれにも見られない波数に吸 収があり，共重合体であることを示している。

\section{4. 結言}

ガスクロマトクラフを用いて未反応モノマーを定量し モノマー反応性比を算出する方法はモノマーの安定性, ポリマーの熱安定性, $r_{1}, r_{2}$ の比が 0.15 7 ぐらいであ ること，モノマーの沸点が高くないこと，およびその他 の条件が具備した場合, 可能となるが，このような重合 反応も多いと思う。しかし, ガスクロマトグラフで得ら れたモノマー消費量と沈殿法によるポリマー収量が一致 しない場合も多く，また，ガスクロマトグラムによる分 析值が既報の元素分析值と一致しない場合もあり ${ }^{2)}$ 今 後, 多くの検討を必要としている。

付 記：本報は高分子学会名古屋大会 (昭和 39 年 11 月) においてその概要を発表した。終りにモ,マーをご提供下さっ た東亜合成化学工業株式会社㳊颜意を表する。

\section{文献}

1) F. R. Mayo, C. Walling: Chem. Rev., 46, 191(1950)

2）伊保内 賢：愛知県工業指導所報告 1, 38(1966)

3) 高分子学会編：高分子実験学講座 10 巻, 134 (1954) （共立出版）

\section{*1 ピーク面積を重量法で求めた埸合の誤差}




\section{Determination of Monomer Reactivity Ratio by Gas Chromatography}

I. Determination of Monomer Reactivity Ratio of Methyl Acrylate and Vinylidene Chloride in Radical Copolymerization

By Masaru Ibonai*

In radical copolymerization of methyl acrylate and vinylidene choride by $\alpha$, $\alpha^{\prime}$-azobisisobutylonitrile in benzene at $60^{\circ} \mathrm{C}$, the monomer reactivity ratio was determined from unreacted monomer contents by gas chromatography. Thus, the terminated copolymerization mixture was injected directly to gas chromatography. Unreacted monomer contents were determined from relative peak area of gas chromatogram and compositions of the copolymer were calculated. The monomer reactivity ratios of methyl acrylate and vinylidene chloride by this method agreed with that of elementary analytical method of chorine analysis.

* Industrial Research Institute, Aichi Prefecture (Hanada-cho, Chikusa-ku, Nagoya) 